\title{
CONTROLLED RELEASE STUDIES OF HYDROXYCHLOROQUINE SULPHATE (HCQ) DRUG-USING BIODEGRADABLE POLYMERIC SODIUM ALGINATE AND LIGNOSULPHONIC ACID BLENDS
}

\author{
S. Giridhar Reddy \\ Department of Chemistry, Amrita School of Engineering, Bengaluru, \\ Amrita Vishwa Vidyapeetham, India-560035 \\ ${ }^{\square}$ Corresponding Author: s_giri@blr.amrita.edu
}

\begin{abstract}
HCQ an antimalarial drug is one of the most in-demand medications globally since COVID-19 pandemics. To study the controlled release of HCQ in physiological environments to address the side effects, biodegradable polymeric blends of Sodium alginate (NaAlg) and Lignosulphonic acid (LS) blends are loaded with HCQ as a model drug. Drug-loaded NaAlg/LS blends of the ratio 80:20 is crosslinked using calcium chloride solutions at different time intervals of time to study HCQ release in different $\mathrm{pH}$ conditions of 1, 4, 7, and 9.2 using a UV-Visible spectrophotometer. The HCQ drug release is studied for its release in variable $\mathrm{pH}$ conditions to mimic the gastrointestinal conditions in the stomach and intestine. The HCQ drug-loaded NaAlg/LS (80:20) blends are also studied for chemical interactions using FT-IR. The results showed that NaAlg/LS (80:20) blends are more suitable carriers and promising strategy for HCQ control release and FTIR results confirm, that HCQ is very much compatible with alginate blend matrix.
\end{abstract}

Keywords: Hydroxychloroquine Sulphate, Biodegradable Polymers, Sodium Alginate, Controlled Release, Hydrogels.

RASĀYAN J. Chem., Vol. 14, No.4, 2021

\section{INTRODUCTION}

The world at its a difficult situation where people are suffering from infections such as Novel Coronavirus disease (COVID-2019) which was described as severe acute respiratory syndrome coronavirus-2 (SARSCoV-2). The scientists are on their toes struggling to cure suffering globally of infections. Several medicines such as Lopinavir and Ritonavir, associate with nursing HIV drug combinations that are tried on Covid-19 treatment have emerged out with side effects include liver injury, nausea, and diarrhea. ${ }^{1}$ These medicines possess a half-life of $\sim 4-6 \mathrm{hr},{ }^{2}$ which means that concentrations can vary by the aspect of eight between peak and trough. By minimizing the drug concentration, developing a controlled-release formulation with zero-order release kinetics to retain the least effective drug concentration may reduce these side effects. Although achieving zero-order in-vivo drug release for an oral or injectable delivery mechanism remains impossible, even formulations with reasonably achievable first-order release kinetics could help minimize toxicity. ${ }^{3-4}$ This strategy is not likely to support all drugs under consideration for COVID-19. However, in the midst of 2020, Hydroxychloroquine sulphate (HCQ) emerged as a prescription drug for COVID-19 infections with a systemic drug concentration that is unlikely to vary dramatically between daily doses due to a biological half-life of approximately 50 days, maximum average drug absorption concentrations are unlikely to differ significantly among daily doses. ${ }^{4-8}$ Clinical trials have reported that in later stages that it induces side effects. ${ }^{9-10}$ Many research articles are reported on how to prevent side effects, in particular biodegradable polymers, which are advanced materials used to mitigate side effects by embedding the drug into its matrix and delivering the drug in a therapeutic range at a controlled dosage. ${ }^{11-15}$

Sodium alginate a seaweed product and Lignosulphonic acid is a plant by-product are the biodegradable polymers available plenty in nature. Sodium alginate is a gel-forming polymer and it has two polymers in Rasayan J. Chem., 14(4), 2209-2215(2021) 
its chain, they are $\alpha$-L-Guluronic acid and $\beta$-D-Mannuronic acid extracted from seaweed product brown algae. ${ }^{16-17} \mathrm{NaAlg}$ is extensively used because of its gel-forming property and non-toxicity in controlling drug delivery applications, sustainable drug delivery, wound healing, scaffolds, biodegradable sutures, interpenetrating networks, food toppings, etc. ${ }^{18-21}$ Lignosulphonic acid is a biodegradable polymer that is commonly used in cement, pesticides, water treatments, dye dispersants, etc. ${ }^{22-24}$ To obtain stable NaAlg beads, LS is blended with NaAlg in various proportions of 80/20,60/40 and 50/50 and these blends are investigated for various properties such as swelling, morphological, crystalline, and drug delivery are reported. ${ }^{25-26}$

Hydroxychloroquine sulphate is typically prescribed for the treatment of malaria, rheumatoid arthritis, and lupus erythematosus. ${ }^{4,27-28}$ The controlled release studies are a significant tool for the design of effective and reliable pharmaceutical products.

An in-depth literature review indicates that no prior studies are available or HCQ control release formulations are reported. In this article, an attempt has been made to report the control release formulations of HCQ loaded in NaAlg/LS blends.

The present study describes the HCQ release in-vitro in the variable $\mathrm{pH}$ medium to imitate the fluids present in the stomach and GI tract. Further HCQ loaded NaAlg /LS (80:20) blends are characterized for drug-polymer interactions and drug compatibility by Fourier Transform Infra-Red (FT-IR) analysis.

\section{Materials}

\section{EXPERIMENTAL}

Biodegradable Sodium alginate (Mw10,000-6,00,000) a seaweed product and Lignosulphonic acid (Mw 52000) a plant by-product purchased from Sigma Aldrich, Bengaluru. Calcium chloride, Hydrochloric acid, Buffer tablets of 4, 7, 9.2 are obtained from Nice chemicals. Hydroxychloroquine sulphate (HCQ) was obtained from IPCA Laboratories Ltd, India. All these chemicals are used as obtained. All experiments are care carried using double distilled water.

\section{Synthesis of Drug Loaded NaAlg/LS (80:20) Blends}

Pre-soaked $4 \%$ Sodium alginate $(\mathrm{NaAlg})$ in $50 \mathrm{ml}$ of double-distilled water, as well as Lignosulphonic acid (LS), are taken in the proportion of (80:20). To this mixture, 20ml of HCQ solution (1mg HCQ/1ml) is added and constantly stirred for 30 minutes using a magnetic stirrer and sonicated for 30 minutes for proper agitation.

\section{Crosslinking of NaAlg /LS Blends}

The HCQ loaded NaAlg/LS viscous mixture in a $5 \mathrm{ml}$ syringe was added dropwise in $25 \mathrm{ml}$ of $2 \% \mathrm{CaCl}_{2}$ solution. The beads are allowed to crosslink for various time intervals of 10, 20, and 30, and 60 mins respectively to form stable beads. After crosslinking the beads are removed from the aqueous solution and dried at $60^{\circ} \mathrm{C}$ for $24 \mathrm{hr}$.

\section{Characterization}

\section{In-Vitro HCQ Drug Release Studies}

The NaAlg /LS (80:20) beads are evaluated for release kinetics of HCQ drug at different $\mathrm{pH}$ solutions. The drug release was studied in 4 typical conditions; $\mathrm{pH} 1(0.1 \mathrm{~N} \mathrm{HCl}) \& \mathrm{pH} 4$ (mixture of Acetic acidSodium acetate), acts as simulated gastric juice (SGF), and pH $7 \& \mathrm{pH} 9.2$ buffer solutions (mixture of $\mathrm{NaH}_{2} \mathrm{PO}_{4}-\mathrm{Na}_{2} \mathrm{HPO}_{4}$ ) acts as simulated intestinal fluid (SIF) were chosen to study the drug release. The drug-loaded beads are taken in $25 \mathrm{ml}$ buffer solutions of $\mathrm{pH} 1,4,7$, and 9.2, and a physiological temperature of $37 \pm 1^{\circ} \mathrm{C}$ is maintained as shown in Fig.-1. At every $1 \mathrm{hr}$ the release of HCQ drug from beads was recorded using Shimadzu 2600 UV-Visible Spectrophotometer at $342 \mathrm{~nm}$ which is a typical peak of HCQ spectrum seen in Figure. 2. HCQ drug release tests were performed in triplicate for each formulation evaluated.

\section{Fourier Transform Infra-Red Spectroscopy Studies}

FT-IR spectra of NaAlg/LS (80:20) blends, HCQ drug, and HCQ loaded NaAlg/LS (80:20) blends are investigated for chemical interaction using Shimadzu Fourier Transform Infra-Red Spectrophotometer, IR Spirit- L, Model no.206-31000-58. The blend composite pellets are made using KBR containing 2-4\% by 
weight of the sample. The samples were scanned within the absorption range of $400-4000 \mathrm{~cm}^{-1}$. The interferogram is generated by the signal process of 45 scans at a resolution rate of $4 \mathrm{~cm}^{-1}$ with LAB SOLUTION software.

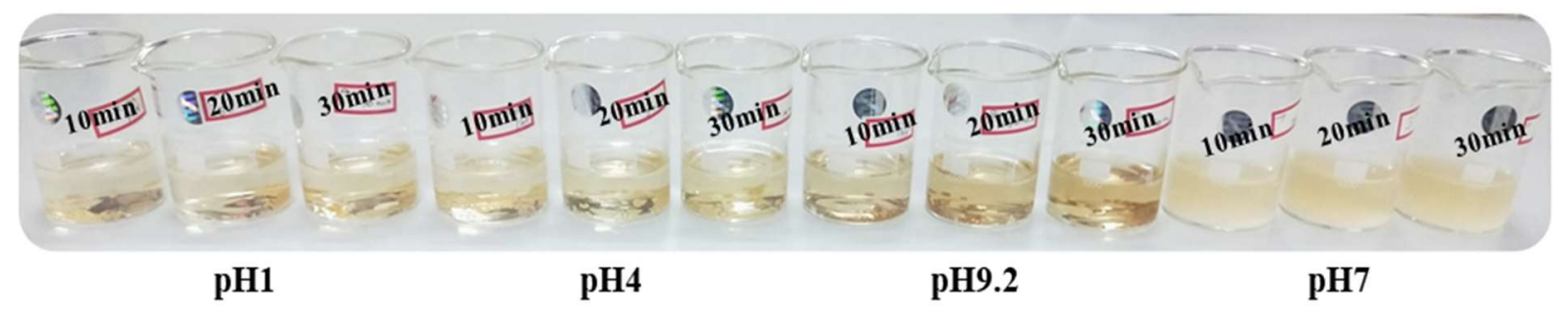

Fig.-1: HCQ Drug release from Crosslinked NaAlg/LS (80/20) Beads in a pH Medium of 1, 4, 9.2 \& 7.

\section{RESULTS AND DISCUSSION}

\section{Control Release Kinetics of HCQ Drug from NaAg/LS Blends}

The HCQ drug-loaded NaAg/LS (80:20) beads are crosslinked for various time intervals (10, 20, 30 mins) are investigated for release of the drug, in different $\mathrm{pH}$ mediums $(1,4,7$, and 9.2) for the reason that, when the drug-loaded beads are taken in-vivo, it passes through the different medium of fluids in stomach, intestine, and colon. To investigate the drug release kinetics and to mitigate different $\mathrm{pH}$ mediums in the human digestive system, the beads are subjected to drug release in different $\mathrm{pH}$ solutions at a physiological temperature of $37 \pm 1^{\circ} \mathrm{C}$. The calibration curve (Fig.-2) is plotted for different HCQ concentrations in $25 \mathrm{ml}$ double distill water for evaluating its release from NaAlg/LS blends in different $\mathrm{pH}$ mediums.

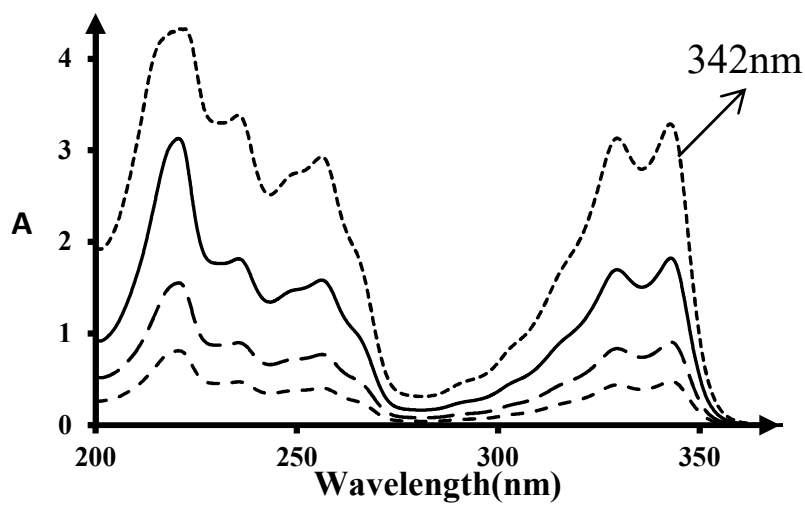

a

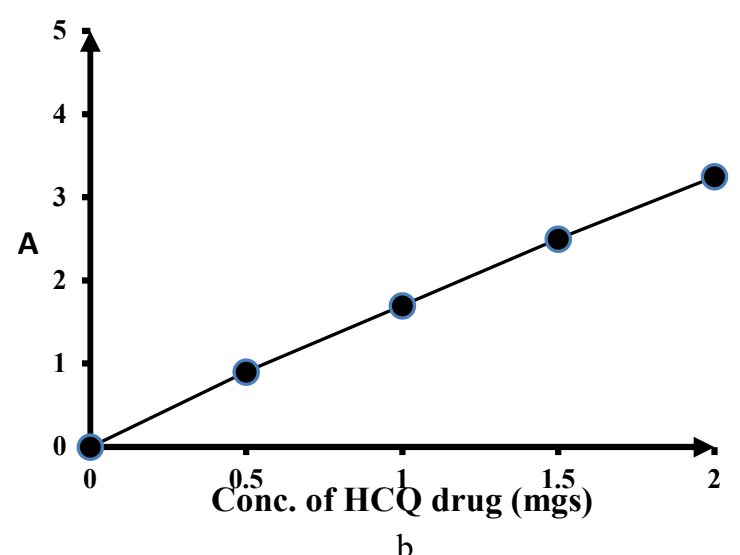

b

Fig.-2: (a) UV Spectra of HCQ Drug, (b) Calibration Curve of HCQ Drug

\section{Release Studies of HCQ Drug in pH 1Medium}

In an aqueous medium of $\mathrm{pH} 1$, the HCQ drug release profiles of NaAlg/LS (80:20) blends of varying crosslinking timings were investigated for $48 \mathrm{hrs}$. It was observed from Fig.-3a, that $10 \mathrm{mins}$ crosslinked beads releases most of the HCQ drug within $7 \mathrm{hrs}$. The plots demonstrate that drug release gradually decreases in 20min crosslinked $\mathrm{NaAlg} / \mathrm{LS}(80 / 20)$ beads and releases a maximum of $70 \pm 6 \%$ HCQ drug in $8 \mathrm{hrs}$, thereafter drug releases constantly up to $24 \mathrm{hr}$ and beyond. $30 \mathrm{~min}$ crosslinked $\mathrm{NaAlg} / \mathrm{LS}$ beads, on the other hand, release only $50 \%$ of the HCQ drug for the first $7 \mathrm{hrs}$ and then release at a very low pace for the next 48 hours. This is because the uronic acid present in NaAlg gels is stabilized with intermolecular hydrogen bonding ${ }^{29}$ and shrinks in alginate structure at low $\mathrm{pH}$, resulting in very low bead swelling.

\section{Release Studies of HCQ Drug in pH 4 Medium}

Similar trends were observed for 30min crosslinking drug-loaded NaAlg/LS (80/20) beads as depicted in pH4 medium (Fig.-3b). Whereas 10- and 20-mins crosslinked blends show more release of HCQ drug compared to $\mathrm{pH} 1$ medium. 
RASĀYAN J. Chem.

Vol. 14 | No. 4 |2209-2215| October- December | 2021

\section{Release Studies of HCQ Drug in pH 7 Medium}

The HCQ drug release was investigated in $\mathrm{pH} 7$ medium, which is considered to be SIF in the GI tract. ${ }^{30}$ The HCQ drug release was very fast in $10 \mathrm{~min}$ crosslinked NaAlg/LS beads and releases the complete drug within 3-4hrs. It was noted that in 10 mins crosslinked NaAlg/LS (80/20) beads develop some cracks, which could be one of the main reasons for the faster release of HCQ drug. The moderate release was observed in 20min crosslinked beads as shown in Fig.-3c, whereas controlled drug release was observed in $30 \mathrm{~min}$ crosslinked beads up to $10 \mathrm{hrs}$. It is reported in our previous publication ${ }^{26}$ that, the rapid release in $10 \mathrm{~min}$ crosslinked beads is because of the exchange of $\mathrm{Ca}^{2+}$ ions present in crosslinked beads with $\mathrm{Na}^{+}$ ions present in $\mathrm{pH} 7\left(\mathrm{Na}_{3} \mathrm{PO}_{4}\right.$ buffer solution). It is noticed and confirmed from results obtained, that time of exposure of NaAlg to crosslinking medium influences the strength of the beads. Since 10min crosslinking beads are exposed for a minimum period may lose their structures in $\mathrm{pH} 7$ medium and promote uptake of more water causing swelling of beads. These swelled beads could not retain the alginate matrix structure and gradually beads start disintegrating (Figure.4), thereby releases most of the HCQ drug. ${ }^{31}$

\section{Release Studies of HCQ Drug in pH 9.2 Medium}

For HCQ drugs, further to elucidate how higher $\mathrm{pH}$ affects the drug release the HCQ loaded NaAlg/LS beads are subjected for swelling and release studies. As shown in Fig.-3d the HCQ drug release was very minimal in pH9.2 because the drug release is swelling dependent and the swelling of beads are very poor in alkaline solutions. ${ }^{32}$ It was observed that only $25-30 \%$ HCQ drug was released up to $48 \mathrm{hrs}$ in 20 and 30min crosslinked beads (Fig.-4c).

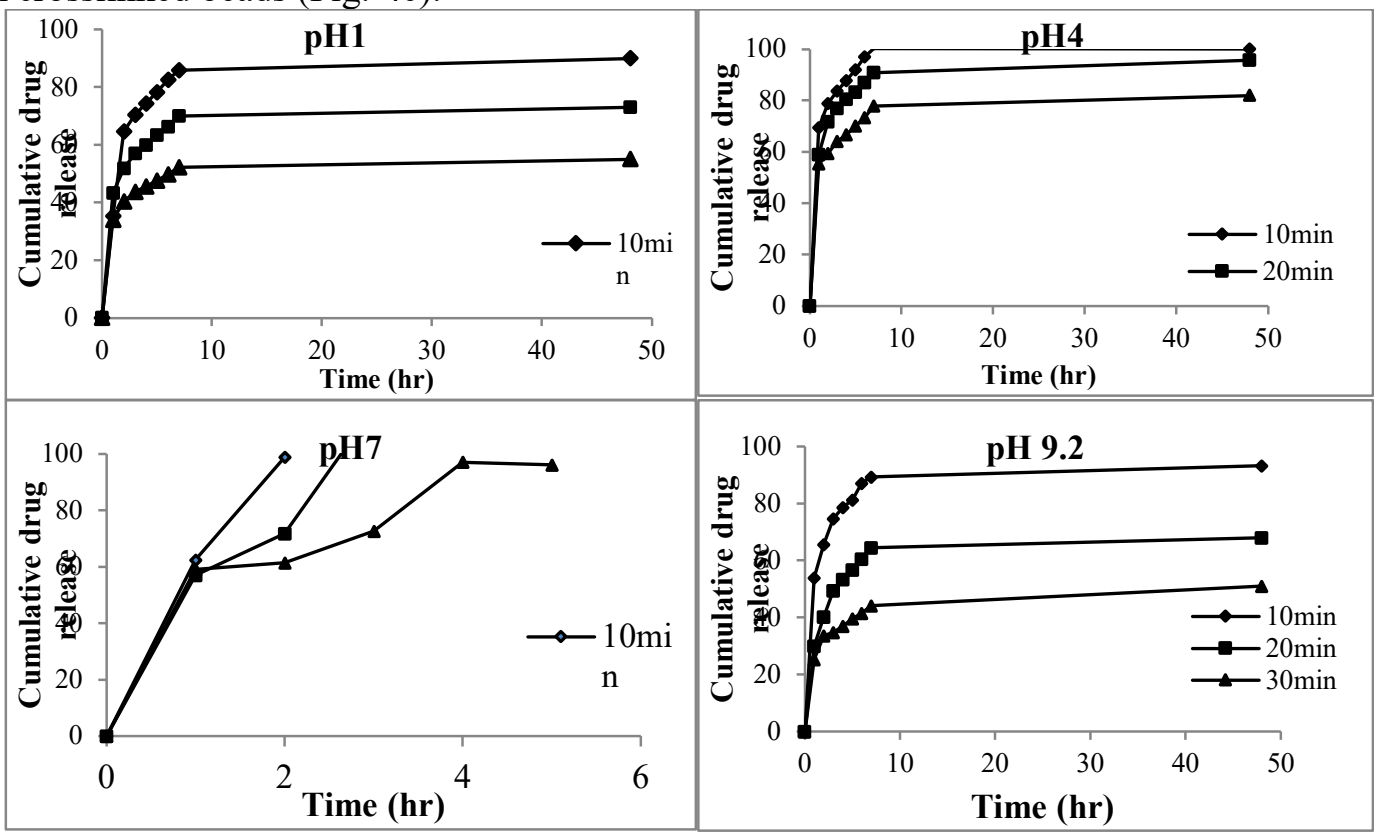

Fig.-3: HCQ Release Profiles of HCQ Drug-loaded NaAlg/LS (80:20) Beads Crosslinked for time intervals of 10, 20 and 30 mins: (a) pH1 (b) pH4 (c) pH7 and (d) pH9.2.

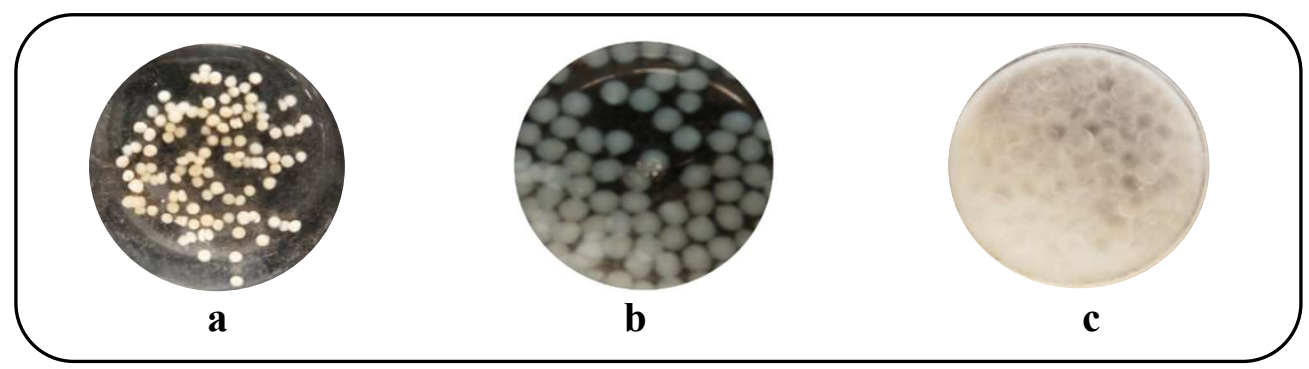

Fig.-4: (a) Dry Beads of HCQ Loaded NaAlg/LS (80:20); (b) Swelled NaAlg/LS (80:20) Beads; (c) Stable Beads releasing HCQ Drug after $48 \mathrm{hr}$. 
RASĀYAN J. Chem.

Vol. 14 | No. 4 |2209-2215| October- December | 2021

\section{HCQ Drug Release in Physiological Medium}

Attempts are made to investigate control release of HCQ drug in a variable $\mathrm{pH}$ solution of 1 and 7 because as drugs are taken orally, it passes through the human digestive system (SGF) for $3 \mathrm{hrs}$ where $\mathrm{pH}$ ranges between 1 to 4 and then passes through intestinal fluids and $\mathrm{pH}$ is between 7 to 9.2. To mimic these digestive systems, the HCQ drug-loaded NaAlg/LS (80:20) beads are allowed to release the drug in a variable $\mathrm{pH}$ medium. The HCQ drug release was very minimum in $\mathrm{pH} 1$ up to $3 \mathrm{hrs}$ as seen in Fig.-5; this is because protonation of sodium alginates in beads doesn't swell much, thereby affecting the drug release. Further, the same $\mathrm{NaAlg} / \mathrm{LS}$ beads are subjected to study the controlled release in $\mathrm{pH} 7$ medium, which is assumed to be $\operatorname{SIF}^{30}$, the beads release $75 \pm 5 \%$ drug up to $12 \mathrm{hrs}$ due to appreciable amount of hydrolysis of alginate beads.

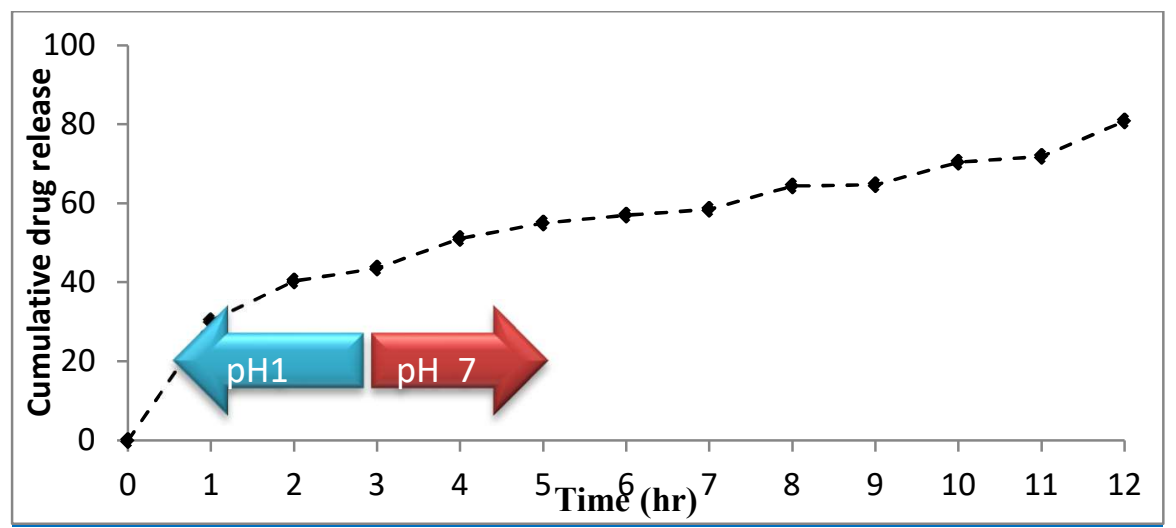

Fig.-5: HCQ Drug Release in the Physiological Medium of pH1 (up to 3hrs) and pH7 (after 3hrs)

\section{FT-IR Studies of HCQ, NaAlg/LS (80:20) and HCQ loaded NaAlg/LS (80:20) Blends}

The FT-IR analysis of HCQ was carried out, the FT-IR absorption spectrum from Fig.-6 reveals the following bands; $3447 \mathrm{~cm}^{-1}$ was due to the $\mathrm{OH}$ group, and the absorption band at $2977 \mathrm{~cm}^{-1}$ is due to $\mathrm{NH}$ deformations. The bands at $3100-2500 \mathrm{~cm}^{-1}$ is indicative of secondary and tertiary amines, with intermolecular interactions within hydrogen bonds overlapping the stretching of the $\mathrm{C}-\mathrm{H}$ group. The axial deformation of aromatic compounds and alkenes by $\mathrm{C}=\mathrm{C}$ and $\mathrm{C}=\mathrm{N}$ bonds shows the absorbance peak at $1622 \mathrm{~cm}^{-1}$. In the bands between 1177 and $1373 \mathrm{~cm}^{-1}$, symmetric and asymmetric deformations of the $\mathrm{S}=\mathrm{O}$ bonds can be seen. Finally, the peaks observed between 550 and $850 \mathrm{~cm}^{-1}$ are due to the $\mathrm{C}-\mathrm{Cl}$ bond..$^{33}$

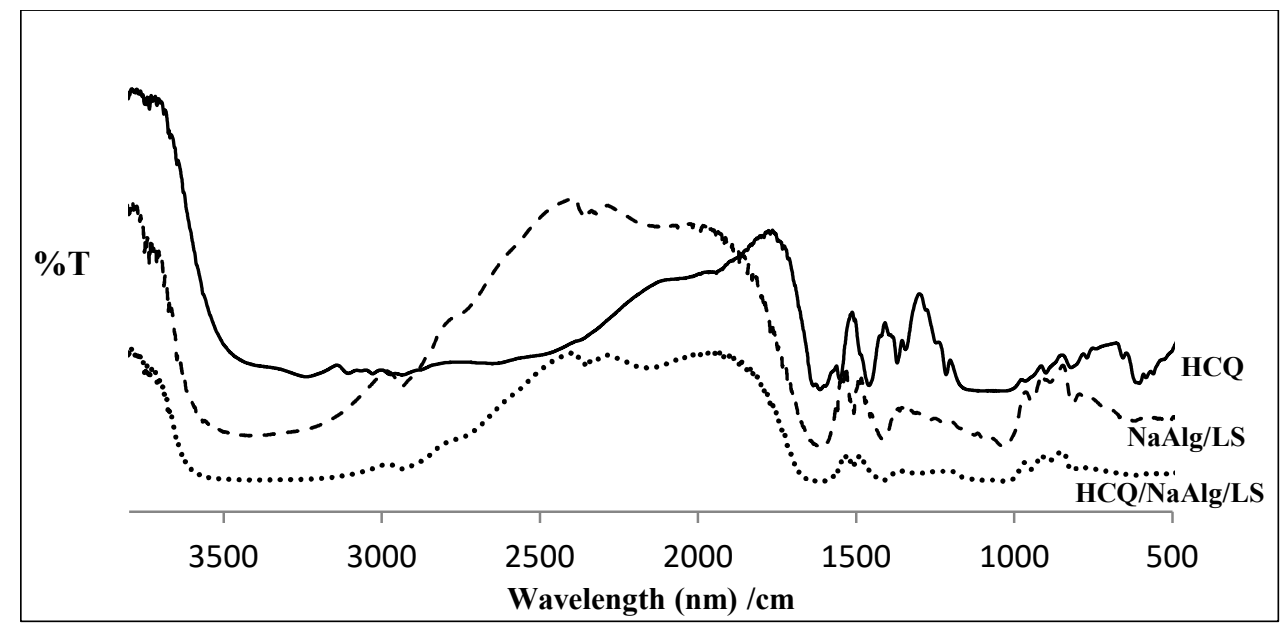

Fig.-6: FT-IR Spectrum of (a) Hydroxychloroquine Sulphate, (b) NaAlg/LS (80:20) Blend, (c) HCQ Drug-loaded $\mathrm{NaAlg} / \mathrm{LS}(80: 20)$

The FT-IR spectrum of NaAlg/LS blends (Fig.-6) shows absorption peaks at 1609 and $1414 \mathrm{~cm}^{-1}$ accounted for the asymmetric and symmetric stretching vibration of the $\mathrm{COO}^{-}$group present in $\mathrm{NaAlg}^{34}$. 
RASĀYAN J. Chem.

Vol. 14 | No. 4 |2209-2215| October- December | 2021

Whereas, absorption peaks at 3442 and $1047 \mathrm{~cm}^{-1}$ are of stretching vibration of the O-H group and C-C stretching of aromatic rings. ${ }^{34}$ On the other hand, the absorption bands due to LS in NaAlg/LS blend, which is observed at 1511 and $1046 \mathrm{~cm}^{-1}$, are attributed to C-C stretching in aromatic rings, whereas 654 $\mathrm{cm}^{-1}$ is due to $=\mathrm{C}-\mathrm{H}$ bending vibration. ${ }^{29}$

An overlap of bands was observed for mixture shows the axial deformation of $-\mathrm{OH}$, $-\mathrm{NH}$, and $-\mathrm{CH}$ present in aromatic compounds present in HCQ drug in the FTIR spectra of HCQ drug-loaded NaAlg/LS (80:20) beads (Fig.-6). The HCQ drug present in the NaAlg/LS matrix is confirmed by the flattening range observed in HCQ loaded NaAlg/LS blends between $990-1183 \mathrm{~cm}^{-1}$, which shows the potential interactions.

\section{CONCLUSION}

Biodegradable blends of NaAlg and LS are used to load HCQ drug and its control release in the physiological medium is reported. HCQ drug is known for its antimalarial dosage prescribed during COVID-19 pandemic situations. Control release profiles of HCQ from the NaAlg/LS matrix are reported to avoid the side effects caused during HCQ treatment. Crosslinking HCQ loaded NaAlg/LS (80/20) beads using calcium chloride are studied, in which crosslinking timings have shown a major role in controlling the release of the drug. It was observed that HCQ drug was released up to $48 \mathrm{hrs}$ and beyond in 30 min crosslinking beads in the gastrointestinal medium. The FT-IR analysis shows that the HCQ drug is compatible and drug concentration is unaffected in NaAlg/LS (80/20) blends. The present investigations describe the control release profiles of HCQ release from NaAlg/LS (80/20) blend and nontoxicity of biodegradable blends which could overcome the side effects. These formulations promote intestinal absorption and demonstrate controlled release to the prolonged periods of therapeutic drug doses. The $\mathrm{NaAlg} / \mathrm{LS}(80 / 20)$ blends are likely to make a very important contribution to be a suitable HCQ drug carrier for the possible effective treatment for COVID-19.

\section{REFERENCES}

1. B. Cao, Y. Wang, D. Wen, The New England Journal of Medicine, 382, 1787(2020), http://doi.org/10.1056/NEJMoa2001282

2. A.Chandwani, Shuter.A,J. Therapeutics and Clinical Risk Management, 4, 1023(2008), http://doi.org/10.2147/tcrm.s3285

3. E. Schrezenmeier, T. Dörner, Nature Reviews Rheumatology, 16, 155(2020), http://doi.org/10.1038/s41584-020-0372-x

4. J.Kevin McHugh, Bioengineering \& Translational Medicine, 5, e10163(2020). https://doi.org/10.1002/btm2.10163.

5. Joshi Poorvashree, Dhaneshwar Suneela, Drug Delivery Translational Research, 7(5), 709(2017), http://doi.org/10.1007/s13346-017-0420-5

6. Jia Liu, Ruiyuan Cao, Mingyue Xu, Xi Wang, Huanyu Zhang, Hengrui Hu, Yufeng Li, Zhihong $\mathrm{Hu}, \mathrm{Wu}$ Zhong \& Manli Wang, Cell Discovery, 6, 16(2020), http://doi.org/10.1038/s41421-0200156-0

7. Oisín Kavanagh, Anne Marie Healy, Francis Dayton, Shane Robinson, Niall J. O'Reilly, Brian Mahoney, Aisling Arthur, Gavin Walker, John P. Farragher, Medical Hypotheses, 143, 110110(2020), http://doi.org/10.1016/j.mehy.2020110110

8. Y. Chen, Y. L. Traore, A. Li, K. R. Fowke, E. A. Ho, Drug Design Development and Therapy, 8, 1801(2014), http://doi.org/10.2147/DDDT.S71352

9. Tzu-Chuan Ho, Yung-Hsuan Wang, Yi-Ling Chen, Wan-Chi Tsai, Che-Hsin Lee, Kuo-Pin Chuang, Yi-Ming Arthur Chen, Cheng-Hui Yuan , Sheng-Yow Ho, Ming-Hui Yang, Yu-Chang Tyan, Pathogens, 10, 217(2021), https://doi.org/10.3390/pathogens10020217

10. Andrey Enrico Alves da Silva, Pedro Manoel Barreto de Abreu, Danilo Costa Geraldes, Laura de Oliveira Nascimento, Journal of Drug Delivery Science and Technology, 63,102512(2021), http://doi.org/10.1016/j.jddst.2021.102512

11. M. Gahlyan, S. Jain, Pharma News, 2021, www.pharmatutor.org/articles/oral-controlled-releasedrug-delivery-system-review 
RASĀYAN J. Chem.

Vol. 14 | No. 4 |2209-2215| October- December | 2021

12. S. Giridhar Reddy, Amrita Thakur, Akanksha Saxena Pandit, Polymer, 40(1), 63(2016), http://doi.org/10.7317/pk.2016.40.1.63

13. B. H. Nanjundareddy, P.Rauta Ranjan, V.Venkatalakshimi, S.Sreenivasa, Materials Research Express, 5, 25403(2018), http://doi.org/10.1088/2053-1591/aaac4c

14. B. C. Thanoo, M. C. Sunny, A. Jayakrishnan, Journal of Pharmacy and Pharmacology, 45(1), 16(1993), http://doi.org/10.1111/j.2042-7158.1993.tb03671.x

15. V. Ramesh Babu, K. S. V. Krishna Rao, M. Sairam, B. Vijaya Kumar Naidu, Kallappa M. Hosamani, Tejraj M. Aminabhavi, Journal of Applied Polymer Science, 99(5) 2671(2006), http://doi.org/10.1002/app.22760

16. V. Pillay, R. Fassihi, Journal of Control Release, 59, 243(1999), http://doi.org/10.1016/s01683659(98)00197-7

17. B. Thu, B. Bruheim, P. Espevik, T. Smidsrod, P. Soon-Shiong, G. Skjak-Braek, Biomaterials, 17, 1031(1996), http://doi.org/10.1016/0142-9612(96)84680-1

18. E. A. Hosny, A. A. M. Al-Helw, Pharmaceutica Acta Helvetiae, 72, 255(1998), http://doi.org/10.1016/s0031-6865(97)00040-x

19. E.A.E.Fattah, D.J.W. Grant, K.E. Gabr, M.M. Meshali, .Drug Development and Industrial Pharmacy, 24, 541(1998), http://doi.org/10.3109/03639049809085655

20. R. Bodmeier, O.Paeratakul, Journal of Pharmaceutical Sciences, 78, 964(1989), http://doi.org/10.1002/jps.2600781117

21. D. Narayanan, Pillai, G. J., Shantikumar V Nair, and Dr. Deepthy Menon, Drug Delivery Translational Research, 9(5), 867(2019), http://doi.org/10.1007/s13346-018-00614-X

22. S, Padmakumar, Bindhu Paul, Pavithran, K, Vijaykumar, D. Kottarathi, Rajanbabu, A., Sivanarayanan, T. Balakrishn, Kadakia, E., Amiji, M. M., Shantikumar V Nair, and Dr. Deepthy Menon, Nanomedicine: Nanotechnology, Biology, and Medicine, 15, 274(2015), http://doi.org/10.1016/j.nano.2018.10.002

23. G.J. Szava, Journal of Power Sources, 28,149(1989), http://doi.org/10.1016/0378-7753(89)80088-6

24. M.Qiu, Q. Wang, Y. Chu, Z.Yuan, H. Song, Z. Chen, Z. Wu, PLoS One, 7, e35906(2012), http://doi.org/10.1371/journal.pone.0035906

25. Amrita Thakur, S.Giridhar Reddy, Journal of Bionanoscience, 12, 780(2018), http://doi.org/10.1166/jbns.2018.1599

26. S.Giridhar Reddy, Akanksha Saxena Pandit, International Journal of Polymeric Materials and Polymeric Biomaterials, 62, 743(2013), http://doi.org/10.1080/00914037.2013.769236

27. Paulo Roberto Bignardi, Carolina Santos Vengrus, Bruno Matos Aquino, Alcindo Cerci Neto, Pathogens and Global Health, 11 Feb 2021, http://doi.org/10.1080/20477724.2021.1884807

28. C. Pushkaran Anju, E. N. Prajeeshnath V. Shantikumar Nair, P. Ram Manohar, C. Gopi Mohan, ChemRxi, (2020).

29. S. N. Pawar, K. J. Edgar, Biomaterials, 33, 3279(2012), http://doi.org/10.1016/j.biomaterials.2012.01.007

30. V. S. R. Krishnaiah, S. Satyanarayan, Y. V. Rama Prasad, S. Narsimharao, Journal of Controlled Release. 55, 245 (1998), https://doi.org/10.1016/S0168-3659(98)00057-1

31. U.J.Mumper, A.S. Hoffman, P.A. Puollakkainer, L.S. Bouchard, W.R.J. Gombotz, Journal Controlled Release, 30, 241(1994), http://doi.org/10.1016/0168-3659(94)90030-2

32. Jui-Jung, Chuang Yu-Ya, Huang, Szu-Hsuan,Lo, Tzu-Fang Hsu , Wen-Ying Huang, Shu-Ling Huang, Yung-Sheng Lin, International Journal of Polymer Science, Article ID 3902704 (2017), http://doi.org/10.1155/2017/3902704

33. Amanda Naves Ferreira Moraes, Luís Antônio Dantas Silva, Maysa Aparecida de Oliveira, Eder Magno de Oliveira, Thais Leite Nascimento, Eliana Martins Lima, Ieda Maria Sapateiro Torres, Danielle Guimarães, Almeida Diniz, Journal of Thermal Analysis and Calorimetry, 140, 2283(2020), http://doi.org/10.1007/s 10973-019-08953-8

34. Qun Wanga, Xianwen Hub, Yumin Dua, F. John Kennedy, Carbohydrate Polymers, 82, 842(2010), http://doi.org/10.1016/j.carbpol.2010.06.004

[RJC-6508/2021] 